\title{
Quantification of the influence of climate on predicted and observed cost of energy for offshore wind
}

\author{
I. Dinwoodie \&. D. McMillan \\ Institute for Energy \& Environment, University of Strathclyde, Glasgow, UK \\ Y. Dalgic \& I. Lazakis \\ Department of Naval Architecture, Ocean and Marine Engineering, University of Strathclyde, Glasgow, UK \\ M. Revie \\ Department of Management Science, University of Strathclyde, Glasgow, UK
}

\begin{abstract}
:
This paper analyses the degree to which lifetime production and availability figures are subject to variation due to inherent inter annual climate variations. This is achieved by performing operational simulations based on different measurement periods chosen from 10 years of historic wind and wave data in the North Sea, establishing the financial implications this has for the industry. The investigation is carried out using a robust Monte Carlo simulation climate and lifetime operational expenditure model. Significant variations are observed with regards to availability, power production and OPEX costs with OPEX costs varying by $15 \%$ above and below the average value when a single year is used for the simulation input. It has also been demonstrated that results with similar availability predictions can have divergent power production and OPEX results. This is explained by the correlations between wind speed, wave height, accessibility and power production. The best practice to minimize uncertainty in cost projections from short term measurement campaigns has been identified.
\end{abstract}

\section{INTRODUCTION}

For onshore wind energy, a detailed wind measurement campaign is required by financiers in order to perform accurate site energy yield assessments. When considering the offshore environment, there is an additional requirement to understand the accessibility of the site, which is determined by the wave climate. Accessibility has a direct impact on the wind farm availability, and a resulting influence on the power production and the financial viability of a project. However, performing climate measurement campaigns in the harsh offshore environment are expensive and also the resulting data sets are frequently of poor quality. Therefore, there is a need to better understand the relationship between wind and wave climates and the resulting cost of energy from offshore wind. In addition, it will be possible to reduce the uncertainty associated with offshore wind by quantifying how the length and the quality of data obtained from a measurement campaign influences the predicted lifetime availability and the energy production values.

Offshore wind power continues to develop towards being a mature source of energy with over 6GW deployed at the end of 2013 worldwide, primarily in Northern Europe (EWEA, 2014). High lifetime cost of energy remains a key barrier to the wide spread deployment of the technology. The high financing and development costs and the uncertainty surrounding the operating phase of the project significantly contribute to the overall project cost. Improved understanding at the design phase of wind farm development therefore presents a significant opportunity for cost reduction at all stages of wind farm life cycle. The key aspects of the design and the commissioning process are the successful design, implementation of a site feasibility study and the resulting lifetime operating cost and revenue calculations.

This study investigates the influence of wind farm climate measurement campaigns on projected operational performance, cost and revenues. This is achieved by using a detailed lifetime operational expenditure (OPEX) and revenue model, StrathOWOM Tool, with a baseline wind farm. Various configurations of climate input measured in the North Sea have then been considered. By keeping all other inputs; wind farm configuration, wind turbine performance and maintenance resource inputs consistent, it is possible to quantify the influence of climate on overall cost of energy calculations. For offshore wind, there is a complex relationship between wind speed, wave height, revenue and OPEX. The developed methodology allows new insights into this relationship and a reduction in the uncertainty and corresponding costs associated with future offshore wind projects. 


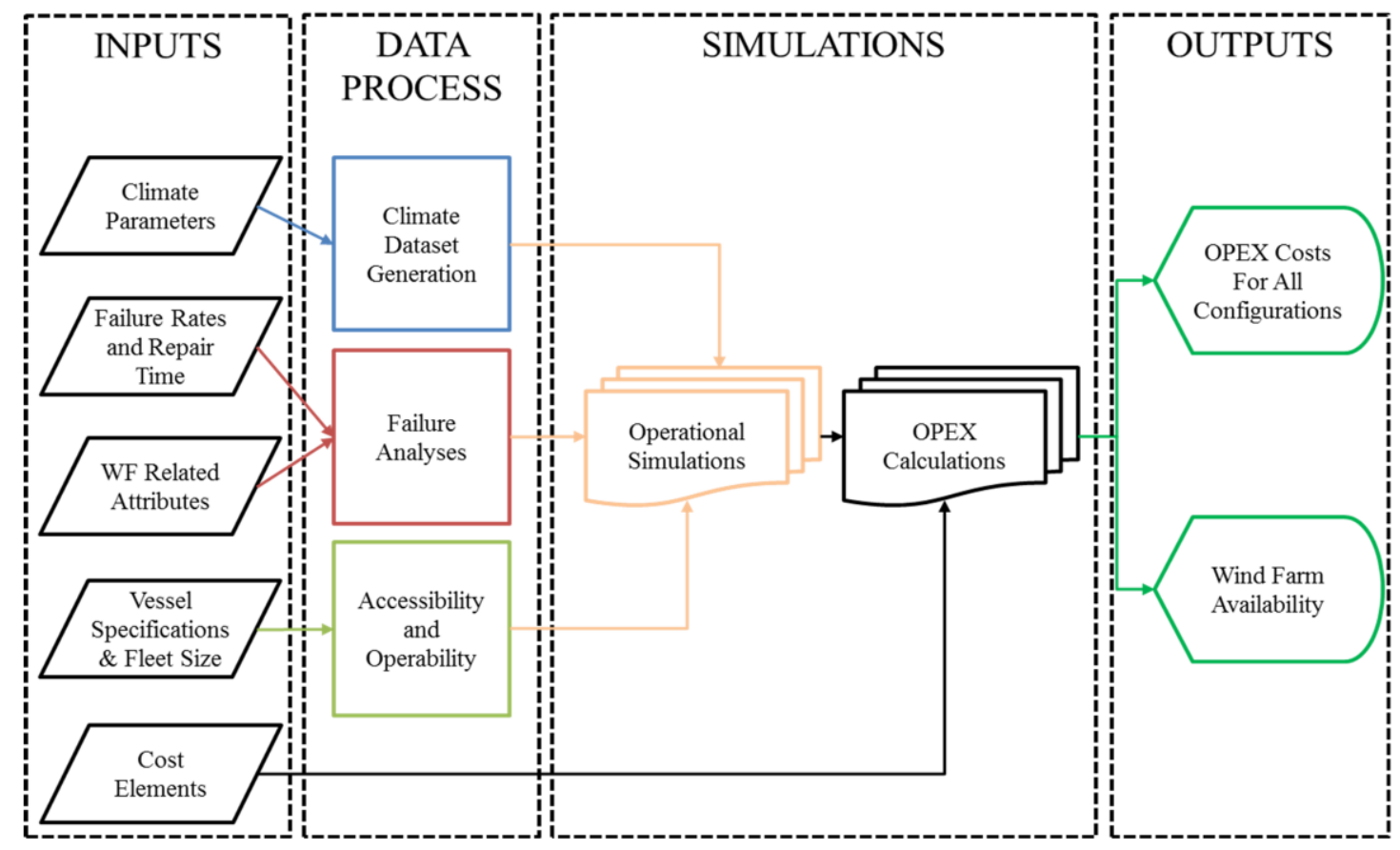

Figure 1. Developed model structure

\section{METHODOLOGY}

The developed methodology is illustrated in Figure 1. The overall model can be considered in four sections: inputs, data process, simulations and outputs. The inputs are taken in and pre-processed to as great a degree as possible to provide common inputs to the lifetime simulations section. In the Simulations block, processed climate series, projected failure behaviors and resource prevision including vessel accessibility and operability values are used to perform lifetime operations simulations. Wind farm operating performance and resource usage are recorded and passed as outputs for post processing OPEX calculations. Wind farm performance can therefore be considered from an availability and power production viewpoint as well as in terms of cost, revenue and profit.

\subsection{Inputs}

The climate parameters, which are used by the model to calculate accessibility and wind turbine performance, are wind speed, wave height and wave period. All climate parameters influence vessel operations as described in Section 2.2.3, wind speed also determines power generation. Failure rates in this study are considered only for the wind turbine system and are described in Table 2, repair time values are the periods associated with actual repair operations with a suitable technician team. All wind farm related attributes are specified in Table 2 .

\subsection{Data processing}

Simulation parameters that can be determined prior to the time series operation simulation are performed in the data process block. This comprises the climate dataset generation, failure analyses, and accessibility $\&$ operability values for each time step of the lifetime simulation. These analyses are explained briefly in the following sections.

\subsubsection{Climate dataset generation}

For this study, the historical climate time series is used directly for all years of simulation. Where more than one year is used as an input, the climate time series for each simulation year is drawn at random from the input time series. Full details of the climate input dataset are described in Section 3.2. The developed model has the capability of generating synthetic wind speed, significant wave height and wave period time series using a Multivariate AutoRegressive (MAR) model, developed from the methodology in (Box \& Jenkins,1970) and (Soares et al, 1996). This approach has not been considered in this analysis but is highlighted as an area requiring further investigation in future work.

\subsubsection{Failure analyses}

The wind turbine system failure process is implemented using the methodology developed in (Billinton, 1970). The wind turbine is characterized as a series of subsystems that can each exist in a discrete state during each simulation time-step. The probability of moving from an operating state to a failed or reduced operating state is governed by the hazard rate $h(t)$, which is defined as the probability of observing a failure in a specified time interval, 1 hour for this study. The hazard rate through the life cycle can be represented using the Weibull function shown in Equation 1, where the shape parameter $\beta$ determines the gradient of the hazard rate and scale parameter $\rho$ corresponds to the frequency of observed failures.

$$
h(t)=\rho \beta t^{\beta-1} \text {, for } \mathrm{t} \geq 0
$$


This methodology allows for changing hazard function throughout the simulated lifetime. As a greater understanding of offshore wind turbine failure behavior is developed through operator experience it will become possible to represent design life changes or impacts of climate and maintenance. For this study constant failure rates are used.

At each time-step a uniformly distributed random number, $N$, in the interval 0 to 1 is generated and used to determine if a failure has occurred using the criteria in Equation 2. Failure transition if:

$$
N>(1-h(t)) \cdot \frac{\Delta t}{8760}
$$

Repair is then simulated based on the climate time series. If a turbine is in a failed state it will return to a working state when sufficient access time has been observed or when a series of repair actions have been performed corresponding to a completed maintenance action.

\subsubsection{Accessibility and operability}

Considering the fact that each time-step in the simulations have different environmental condition, the accessibility and the operability of vessels may vary from day to day. In addition, the transit time may change depending on the climate conditions in a repair day. The transit time is important to identify the time-step that the actual repair activity can start. In the first step of the accessibility and operability analyses, the days that the vessels cannot operate or access the site due to rough weather are identified through investigating the weather conditions and the vessel operability limitations. Thereafter, the transit time calculations are performed for the accessible days, which the vessel may potential perform a visit to the site. In this context, vessel resistance calculations are performed prior to the transit time calculations. The resistance calculations provide information to calculate the speed loss due to waves.

The total calm water resistance $R_{T-C a l m}$ of the vessels can be calculated from the Equation 3;

$$
R_{T-\text { Calm }}=P_{E} / V
$$

where $P_{E}=$ effective power and $V=$ vessel speed.

In heavy seas, waves cause additional resistance on the vessel hull. Jinkine \& Ferdinande, 1973 developed an empirical formulation for predicting the added resistance for fast cargo ships in head seas. The dimensional added resistance is related to the non-dimensional added resistance coefficient by Equation 4

$$
R_{A W}=\sigma_{A W}\left(\rho g \zeta_{A}^{2} B^{2} / L\right)
$$

Where $R_{A W}$ is non-dimensional added resistant coefficient, $\sigma_{A W}$ is non-dimensional added resistant coef- ficient, and $\zeta_{A}$ is wave amplitude; $\rho$ is density of water, $g$ is acceleration due to gravity, $B$ breadth of vessel, and $L$ is length of vessel. The total resistance of the vessel, $R_{T}$ is the summation of calm water resistance and added resistance due to waves in the ocean, shown in Equation 5.

$$
R_{T}=R_{A W}+R_{T-\text { Calm }}
$$

In this study the power and thrust of the vessels will be kept constant and speed will change with the influence of added resistance. In order to calculate the speed loss in each time-step under the condition of constant power and thrust, Equation 6, derived by (Berlekom, \& Dellhag, 1974) and (Berlekom, 1981) can be utilized. When the summation of these distances become equal to the total distance between port and offshore wind farm, it is accepted that the vessel has approached to the wind farm site shown in Equation 7.

$$
\begin{aligned}
& V_{A_{i}}=V_{0}-V_{0} \sqrt{1+\frac{R_{A W_{i}}}{R_{T_{i}}}} \\
& \text { Distance }_{i}=\text { Time Step Interval } \times V_{A_{i}}
\end{aligned}
$$

where $R_{A W i}=$ Added resistance at time-step $i ; R_{A W}=$ Total resistance at time-step $i, V_{o}=$ Operational speed of vessel; $V_{A i}=$ Achievable speed at time-step $i$.

\subsection{Simulations block}

The simulations are performed through synthesizing all processed climate, failure and operational information received from data process block. At the beginning of each simulated shift, any failure that has occurred is assigned to the specified turbines subsystem. In order to perform repair actions, available resources and accessibility are considered. Working hours are limited by a specified shift duration to represent current working practices. However, climate parameters may not allow vessels to leave the port or transport technicians to wind farm within specified shift or allow only a limited period in the shift. Therefore, the maximum weather window is calculated for each shift in order to identify the maximum period that the technicians can work, which is then used to determine maintenance carried out.

If a sufficient repair window is available to travel to and from the wind farm and repairs or corrective maintenance are required to be performed, a vessel is allocated to a turbine. Repairs are cumulative, which means if the repair cannot be completed within a single shift, the remaining part can be completed in the next accessible shift. When a repair day is completed, the following day is simulated. A simulation run is completed when all operating shifts in the wind farm life cycle have been simulated. This process is repeated for a large number of simulation 
runs and results passed to the output block to provide expected values as well as a range of observable states.

\subsection{Outputs block}

The model can output a wide range of metrics with which to consider wind farm performance. For this study the focus is on wind farm availability, the power produced and OPEX per MWhr cost. Availability is a widely used metric for measuring wind farm performance and is defined in Equation 11

$$
\text { Availability }=1-\frac{\text { Unavailable Time }}{\text { AvailableTime }+ \text { Unavailable Time }}
$$

OPEX per MWhr considers the direct maintenance cost and reflects the power produced which is driven by climate and wind farm availability. Therefore it is the most appropriate metric with which to determine the cost of energy. This will determine whether a project is financially viable and this metric is therefore critical to the objective of this study.

Power produced is determined using the wind turbine power curve and the instantaneous wind speed in the simulated time series. The power calculation is determined for each time step using Equation 12 from (Burton et al, 2001) where $\mathrm{P}(\mathrm{t})$ is power produced, $\mathrm{U}(\mathrm{t})$ is the instantaneous wind speed, $\mathrm{p}(\mathrm{u})$ is the power production value at a given wind speed and $\eta$ is an efficiency term to account for wake and inter array losses. The power curve is taken from (Jonkman, 2009) and is shown in Figure 2.

$$
P(t)=U(t) \cdot p(u) \cdot \eta
$$

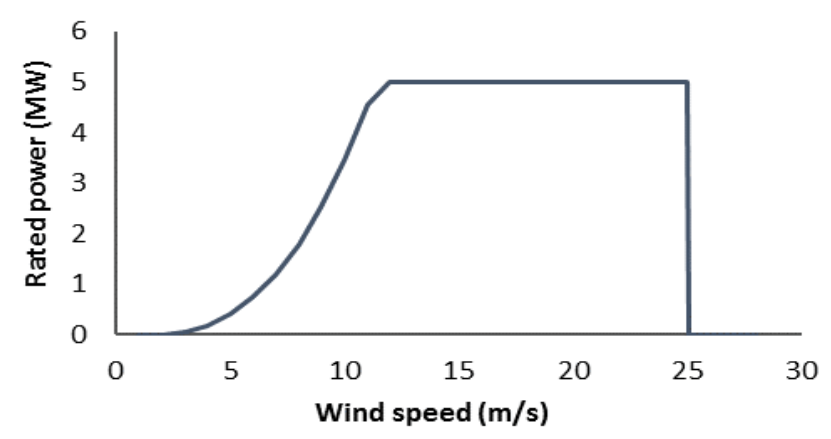

Figure 2: Wind turbine power curve

\section{DATA SOURCE ANALYSIS}

\subsection{Wind and wave data requirements, measurement and quality}

When considering if a location is suitable for an onshore wind farm, it is necessary to perform a measurement campaign of the wind conditions. This is required in order to estimate the energy yield at the site and determine the economic viability of the project. Offshore, wind conditions also influence the ability to perform maintenance activity. The primary influence on accessibility for maintenance in the offshore environment is wave conditions. However, there is a correlation between wind speed and wave characteristics and a nonlinear relationship on cost of energy. More benign wind and wave conditions will increase availability of the wind farm but may reduce power produced. It is therefore necessary to perform an assessment of site wave climate in order to accurately estimate the lifetime cost of energy for a prospective wind farm.

Onshore, there is a requirement to perform a 2 year measurement campaign using a meteorological mast with a cup anemometer (Burton et al, 2001). This can then be augmented to a longer time series using nearby historical data sets from permanent weather stations using techniques such as MeasureCorrelate-Predict (MCP) in order to provide a longer term estimate of the wind resource. It should be noted that in sites with complex topography the measurement campaign may be augmented using more sophisticated measurement techniques such as LIDAR in order to provide greater insight into the expected performance of the wind farm but these additional sources of measurement are not used for financing purposes. Anemometers are low cost components and multiple can be deployed on a single met mast in order to reliably produce a high quality wind data set. In cases where a fault develops there is a low associated repair cost. The methodology for onshore measurement campaigns are therefore well established and can be considered to present low risk to the overall wind farm development cost.

In the offshore environment there is an increased complexity, cost and risk associated with climate measurement campaigns. The installation of an offshore met mast in order to measure wind speed is extremely expensive and costly to repair if there is any failure of equipment. Additional complexity arises from equipment for measurement of wave climate using a data buoy. The extremely harsh nature of the sea climate results in poor reliability as well as expensive hardware and maintenance costs when gathering data. Consequently, wave climate data sets are more likely to have significant gaps and there is a financial benefit from making lifetime cost of energy calculations based on as short a data set as possible.

\subsection{FINO data set}

There are various sources of short term measured wave time series available in European waters, for example the Wavenet database. However, these are not of a sufficiently long period to investigate the uncertainty that arises from inter-annual variability and in most cases do not contain a concurrent wind speed time series. The FINO 1 research mast, located $45 \mathrm{~km}$ off the coast of Germany provides an appropriate data set for this analysis. In addition, the met mast is located within the German offshore wind development zone and can therefore be considered representative of current and future offshore wind farms in Europe. The mast has been collecting climate data 
since 2004 , for this study the period $2004-2012$ inclusive has been used. The overall quality of data in this period is summarized in Table 1 . It can be seen that there remains significant gaps in the data due to the inherent difficulty in collecting data in the offshore environment. For this study, these gaps have been filled using a cubic spline. While this undermines the confidence in the absolute results values observed for those periods, it demonstrates the underlying challenge associated with offshore data.

Table 1. Data quality, percentage of data set without gaps

\begin{tabular}{cc} 
Year & Data quality \\
\hline 2004 & $76.2 \%$ \\
2005 & $98.4 \%$ \\
2006 & $95.0 \%$ \\
2007 & $92.1 \%$ \\
2008 & $93.7 \%$ \\
2009 & $80.5 \%$ \\
2010 & $74.8 \%$ \\
2011 & $92.7 \%$ \\
2012 & $99.9 \%$ \\
All years & $89.9 \%$ \\
\hline
\end{tabular}

\section{CASE STUDIES AND ANALYSIS}

\subsection{Analysis description}

Using the FINO data set and the lifetime OPEX simulation model, two series of analysis were carried out. Firstly, each year from the data set was used as the climate input data, in all scenarios the wind farm configuration, failure performance and resource provisions were kept consistent. This enables the range of lifetime performance estimates that a potential developer would encounter to be determined, dependent on the year of measurement campaign. Secondly, the result of using a cumulative time series starting at 1 year and increasing by a year for each simulation until the complete data set is used. This enables the benefit of longer time series to be quantified and considered against the associated increased cost and time requirement.

Table 2. Baseline wind farm specification

\begin{tabular}{lcc}
\multicolumn{1}{c}{ Input } & Value & Notes \\
\hline $\begin{array}{l}\text { Number of turbines } \\
\text { Distance to shore }\end{array}$ & $50 \mathrm{~km}$ & \\
\hline $\begin{array}{l}\text { Number of vessels } \\
\text { Wind turbine rating }\end{array}$ & $5 \mathrm{MW}$ & Jonkman, 2009 \\
\hline $\begin{array}{l}\text { Total failure rate } \\
\begin{array}{l}\text { Annual scheduled } \\
\text { maintenance }\end{array}\end{array}$ & 7.5 & $\begin{array}{c}\text { Dinwoodie et al, 2013 } \\
\text { and Wilkinson, 2007 }\end{array}$ \\
\hline
\end{tabular}

\begin{tabular}{ll}
\hline Cost values & $\begin{array}{c}\text { Dalgic et al, 2014, } \\
\text { Lazakis et al, 2013 }\end{array}$ \\
\hline
\end{tabular}

As well as availability, it is necessary to examine the power production values in order to determine the overall influence of climate on cost of energy. In addition to the predicted lifetime availability and power production, the annual values observed across all simulations are recorded and can be used to produce a probability density function for each year. This allows the confidence value of a project to be determined and provides greater insight into the consequence of different measurement campaigns. The wind farm specification is detailed in Table 2.

\section{RESULTS}

\subsection{OPEX estimates from individual years}

The lifetime availability and cost values associated with using each year of the data set are shown in Table 3 and the absolute deviation from the mean of all simulations shown in Table 4. From Tables 3 and 4, it can be seen that there is significant inter annual variation in all three metrics. The average deviation observed in power production and OPEX costs are significantly larger than the deviation in availability. The most significant deviation from the mean value in percentage terms is observed in 2010, where OPEX costs are $14 \%$ above the mean value despite availability being $1.73 \%$ higher than average. This highlights the need to explore wind and wave climate when evaluating lifetime cost of energy.

Table 3. Results using individual years and entire data set

\begin{tabular}{cccc} 
Year & $\begin{array}{c}\text { Availability } \\
(\%)\end{array}$ & $\begin{array}{c}\text { Power } \\
\text { Produced }(\mathrm{GWhr})\end{array}$ & $\begin{array}{c}\text { OPEX cost } \\
(£ / \mathrm{MWh})\end{array}$ \\
\hline 2004 & $86.7 \%$ & $3.61 \mathrm{E}+04$ & 14.8 \\
2005 & $90.1 \%$ & $3.96 \mathrm{E}+04$ & 13.5 \\
2006 & $86.0 \%$ & $3.66 \mathrm{E}+04$ & 14.6 \\
2007 & $82.5 \%$ & $3.68 \mathrm{E}+04$ & 14.6 \\
2008 & $88.2 \%$ & $4.22 \mathrm{E}+04$ & 127 \\
2009 & $86.8 \%$ & $3.79 \mathrm{E}+04$ & 14.3 \\
2010 & $87.9 \%$ & $3.25 \mathrm{E}+04$ & 16.5 \\
2011 & $80.0 \%$ & $3.40 \mathrm{E}+04$ & 15.4 \\
2012 & $91.8 \%$ & $3.93 \mathrm{E}+04$ & 13.6 \\
\hline All years & $86.4 \%$ & $3.71 \mathrm{E}+04$ & 14.5 \\
\hline
\end{tabular}

Table 4. Percentage deviation from mean value across sims

\begin{tabular}{cccc} 
Year & Availability & $\begin{array}{c}\text { Power } \\
\text { Produced }\end{array}$ & OPEX cost \\
\hline 2004 & $0.10 \%$ & $-2.92 \%$ & $2.34 \%$ \\
2005 & $4.00 \%$ & $6.48 \%$ & $-6.70 \%$ \\
2006 & $-0.74 \%$ & $-1.80 \%$ & $1.21 \%$ \\
2007 & $-4.80 \%$ & $-1.01 \%$ & $1.00 \%$ \\
2008 & $1.77 \%$ & $13.5 \%$ & $-12.3 \%$ \\
2009 & $0.21 \%$ & $1.73 \%$ & $-0.96 \%$ \\
2010 & $1.49 \%$ & $-12.6 \%$ & $14.3 \%$ \\
2011 & $-7.74 \%$ & $-8.72 \%$ & $6.73 \%$ \\
2012 & $5.94 \%$ & $5.69 \%$ & $-5.76 \%$ \\
All years & $-0.24 \%$ & $-0.33 \%$ & $0.15 \%$ \\
\hline *Absolute & $2.94 \%$ & $6.06 \%$ & $5.71 \%$ \\
mean error & 2.94 & & \\
\hline
\end{tabular}

*excluding 'All years' simulation 


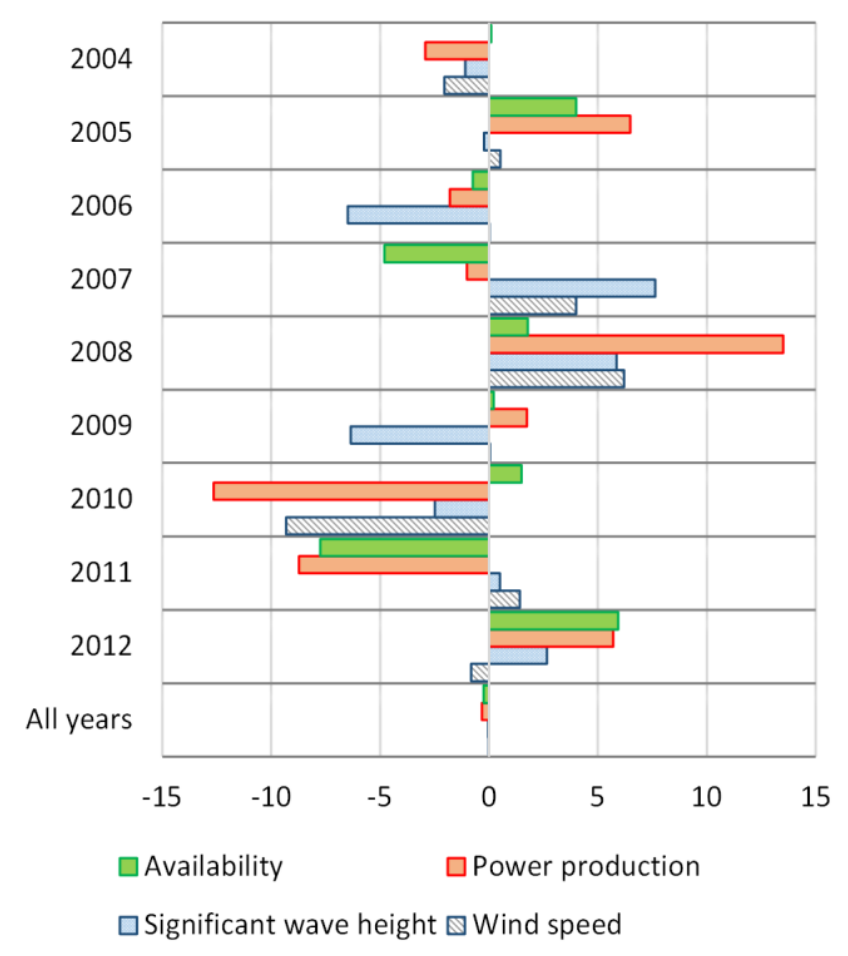

Figure 3. Performance and environmental deviation from mean values

A clearer indication of what is contributing to the results in Table 3 can be provided by considering Figure 3 which shows the annual percentage deviation of availability, power production, mean wind speed and mean significant wave height. It can be seen that power production is correlated directly to wind speed and availability but wind speed and wave height are negatively correlated to availability. Consequently, there is a complex relationship amongst the variables across years. The seasonal variation in climate, availability and power production in different years can further explain the inter dependencies.

For clarity, three categories of years are considered in Figure 4-4. Firstly, years with similar availability but significantly different power production are considered by looking at the monthly values of 2008 and 2010. Then low availability years of 2007 and 2011 are considered and finally high availability years of 2005 and 2012 examined.

From Figure 4 it can be seen that with the exception of March 2008, the wave conditions are very close to the long term mean which results in availabilities within $2 \%$ of the baseline. However, 2008 has a significantly higher wind speed profile than 2010. The average wind speed in 2008 is higher in 10 of 12 months with an average difference of 1.6 $\mathrm{m} / \mathrm{s}$. In the key power producing months of January - March this difference is $2.7 \mathrm{~m} / \mathrm{s}$ which results in the lower power production values for 2010 .

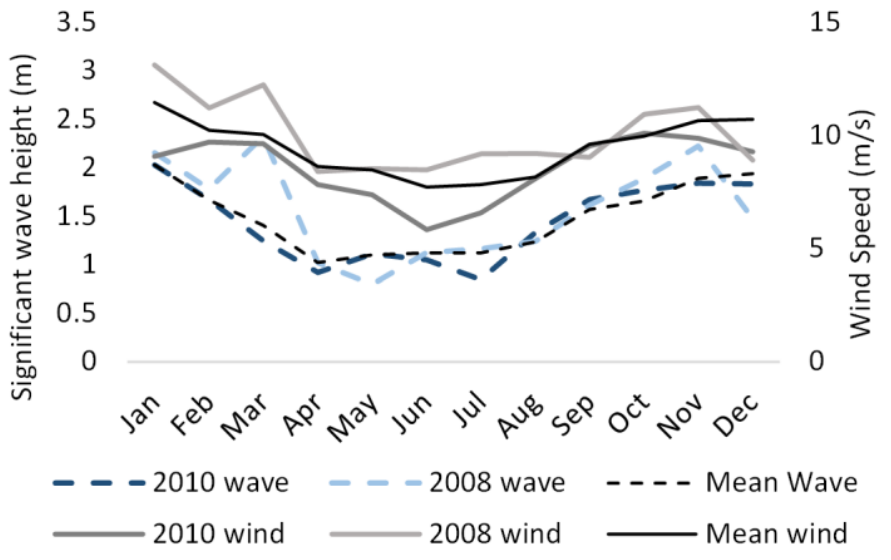

Figure 4. Comparison of 2008 and 2010

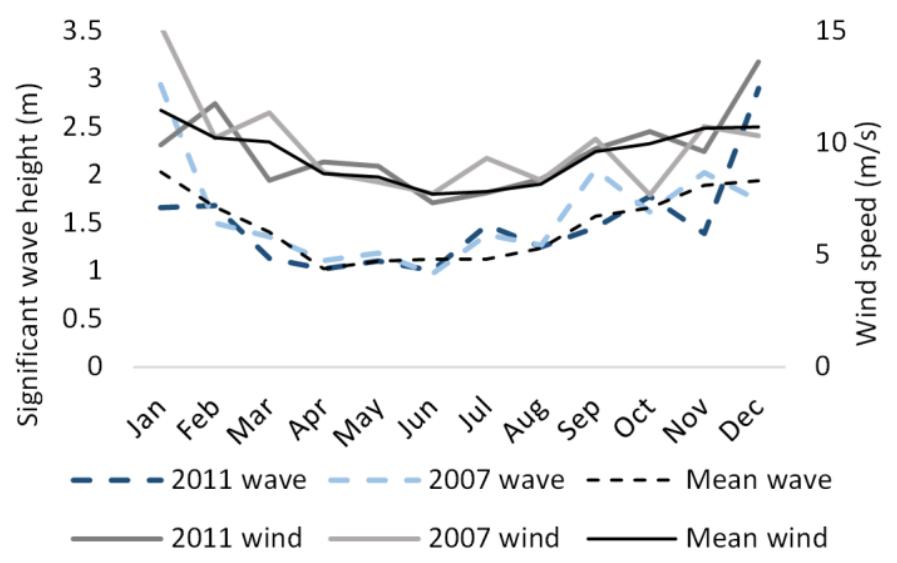

Figure 5. Comparison of 2011 and 2007, 'poor' years

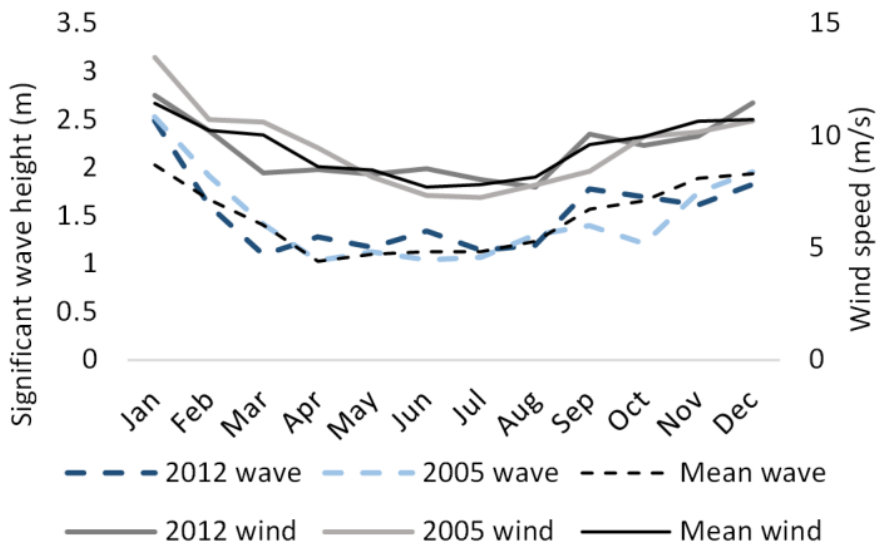

Figure 6. Comparison of 2005 and 2012, 'good' years

In order to consider the key drivers for low and high availability years it is necessary to examine the years with lowest and highest availability. The low availability years, classed as poor are 2007 and 2011 and years with highest availability, classed as good years are 2005 and 2012. From Figure 5 it can be seen that it is only necessary for 2-3 months of higher than average wave heights to result in low availability if those months are 1-2 m higher than the average significant wave height for that month, taking the value above the $1.5 \mathrm{~m}$ access threshold. The resulting low availability can be explained from a simulation context as the regular period of high wave height with poor accessibility will create an interval 
where no maintenance is carried out. Consequently, when it is possible to access the wind farm there will be insufficient resource available to perform maintenance and a bottle-neck effect will occur. Examining Figure 6, it can be seen that both years have a number of months where average wave height is above the average. Critically however, there are only 3 out of the 24 months in the two years where the average wave height is greater than $1.5 \mathrm{~m}$ compared with 8 months across 2008 and 2010.

Considering the variation across all years the most critical value from a project financing is the OPEX cost. It can be seen from Table 4 that the largest opportunity for error comes from years with similar availability profiles but differing power production values. In this respect it is critical that both the wind and wave values from a measurement campaign are compared to a long term average values from climate records to identify and budget for this scenario.

The range of availability values that are anticipated using individual years and the entire data set are shown in Figure 7. From this it can be seen that relying on a single year does not allow the full range of performance to be simulated. The problem is exacerbated in the four years classified as 'poor' and 'good' where a repeated narrow range of results are observed. In order to correctly budget for a project it is desirable to understand the likelihood of the full range of operating scenarios. Therefore it is evident that using as large a data set as possible is the optimum solution from a project risk viewpoint.

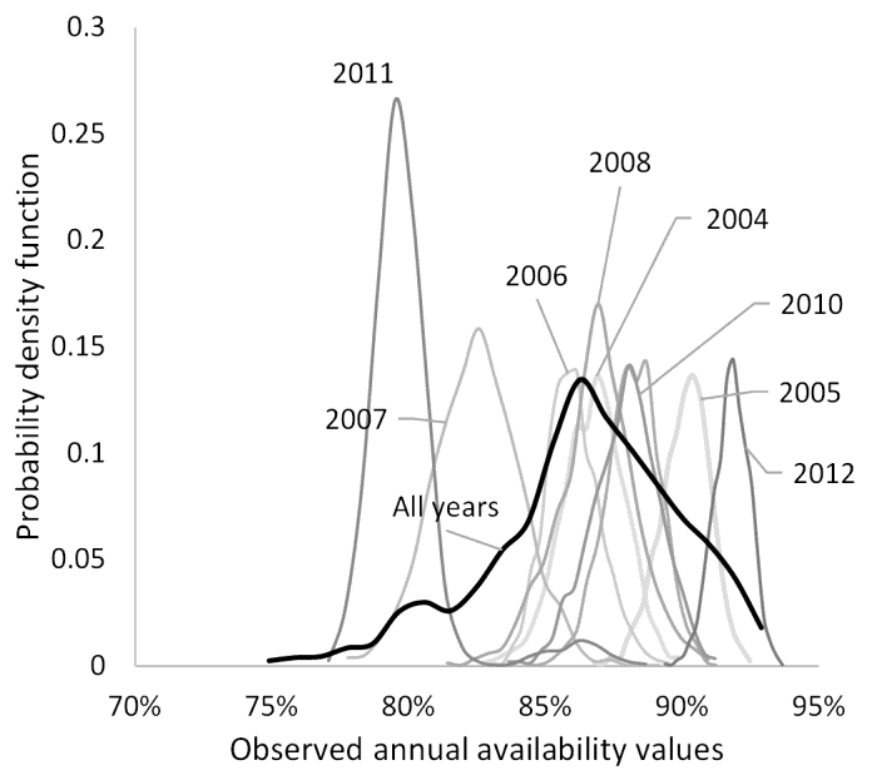

Figure 7. PDF of availability distributions for each year in data set

\subsection{Influence of increasing length of measurement campaign}

The desire for a long measurement campaign must be offset by the cost and delay to commissioning and generation that is associated with long measurement campaigns. The lifetime OPEX simulation model has therefore been run for differing lengths from 1 year to the full data set. The resulting outputs are shown in Table 5. There is a weak trend of reduction in uncertainty with increasing years. The values are subject to significant deviation from a single year, even in the longer time series. From this analysis it isn't possible to quantify the reduction in uncertainty with increasing measurement campaign length. However, the absolute values are lower than those observed in Table 4.

Table 5. Percentage deviation from mean value across sims

\begin{tabular}{cccc} 
Year & Availability & $\begin{array}{c}\text { Power } \\
\text { Produced }\end{array}$ & OPEX cost \\
\hline 1 year & $0.19 \%$ & $-2.95 \%$ & $-0.19 \%$ \\
2 years & $1.36 \%$ & $0.77 \%$ & $-0.49 \%$ \\
3 years & $0.60 \%$ & $-0.27 \%$ & $-0.49 \%$ \\
4 years & $-0.80 \%$ & $-0.59 \%$ & $-0.01 \%$ \\
5 years & $-0.16 \%$ & $2.54 \%$ & $-0.39 \%$ \\
6 years & $-0.07 \%$ & $2.08 \%$ & $0.53 \%$ \\
7 years & $-0.17 \%$ & $-0.14 \%$ & $0.22 \%$ \\
8 years & $-0.80 \%$ & $-1.07 \%$ & $0.56 \%$ \\
9 years & $-0.16 \%$ & $-0.37 \%$ & $0.27 \%$ \\
\hline
\end{tabular}

The range of simulated annual availabilities is shown for all measurement campaign lengths in Figure 8 .

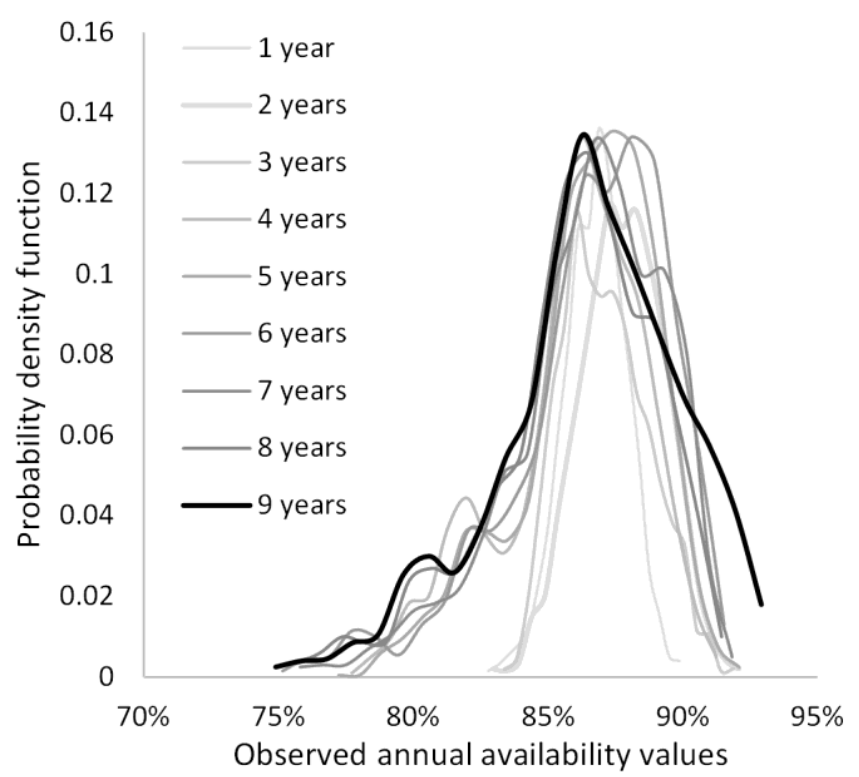

Figure 8. PDF of availability with increasing time series length

For the FINO dataset, there are two regions in the PDF plot. For input data sets less than 4 years the predicted range of performance falls within a range of $83-93 \%$ availability. With the inclusion of a poor year in 2007 the simulated availability range increases from $75 \%$ to $93 \%$. Increasing beyond this range has limited influence on the predicted distribution. The key requirement for this scenario is that the measurement campaign a set of years that can be considered 'poor' and 'good' relative to the long term average value that have been recorded. 


\section{FUTURE WORK}

This paper has considered a range of cases based on different observation periods within the longer data set. However, it has not been exhaustive and further insight may be provided by considering a wider range of scenarios. By considering different sets of years it would be possible to identify the shortest measurement campaign that can be used as model input to produce lifetime results that are representative of the full range of operating scenarios which would be observed.

Additionally, where only one or two years of data are available, the use of simulation methods to produce synthetic time series may allow for increased confidence in results. By preserving key climate characteristics, including seasonality while introducing a random component to vary inter-annual performance it will be possible to simulate a wider range of scenarios from a smaller measurement campaign. In order to fully quantify this approach it is necessary to run the model with a significant measured data set and operational data from a wind farm. Such a data set does not currently exist but will be generated by operators for existing sites. These data can be used to better predict the remaining OPEX cost for operating wind farms as well as reduce the cost of future site climate measurement campaigns.

An additional area for further study is the degree to which increasing or improving the maintenance resources such as vessel and technicians can reduce the uncertainty influence that arises from climate. Having more resource available has the potential to overcome the bottle-neck effect that arises after months with poor accessibility while increasing the access threshold may alleviate the issue.

\section{CONCLUSIONS}

This paper has explored the influence of wind and wave climate on the lifetime operational performance and cost of offshore wind farms. The analysis has focused on the degree to which lifetime cost estimates change when different years or segments from a measurement campaign at a single site are used to inform the lifetime analysis. Significant variation is observed with regards to availability, power production and OPEX costs for different years with OPEX costs varying by $15 \%$ above and below the average value when a single year is used for the simulation input. The analysis has identified that availability is less sensitive to individual year selection. It is also demonstrated that the results with similar availability predictions can have divergent power production and OPEX results. This is explained by the correlations between wind speed, wave height, accessibility, and power production.
It is therefore recommended that a measurement campaign should be compared to available long term mean wind speed and wave height values available from hindcast data or nearby measurement campaigns in order to inform lifetime cost estimates more accurately. In addition, longer term measurement campaigns reduce the uncertainty of results. However, there is a clearer benefit from using a data set that contains a combination of 'poor' years with below average wind speed and 'good' operating years than from a longer data set that contains similar years. The analysis should also be carried out throughout the lifetime of a wind farm as operational climate data is obtained to improve financial forecasting for the remainder of the wind farm project.

\section{REFERENCES}

Burton, T., Sharpe, D., Jenkins, N. \& Bossanyi, E. 2001. Wind Energy Handbook, Wiley

Berlekom, W.B.V. 1981. Wind Forces on Modern Ship Forms - Effects on Performance. Transactions of the North East Institute of Engineers and Shipbuilders, 97. 123-132

Berlekom, W.B.V., Tragardh, P. \& Dellhag, A. 1974. Large tankers - Wind coefficients and speed loss due to wind and sea, Naval Architect, 1, Royal Institution of Naval Architects.

Billinton, R. 1970. Power system reliability evaluation, New York, Gordon and Breach.

Box, G.E.P. \& Jenkins, G.M. 1970. Time series analysis: forecasting and control, McGraw-Hill.

Dalgic, Y., Dinwoodie, I., Lazakis, I., McMillan, D. \& Revie, M. 2014. Optimum CTV fleet selection for offshore wind farm O\&M activities. Safety and Reliability: Methodology and Applications - Nowakowski et al. (Eds)

Dinwoodie, I., McMillan, D., Revie, M., Lazakis, I. \& Dalgic, Y. 2013. Development of a Combined Operational and Strategic Decision Support Model for Offshore Wind. Energy Procedia, 35, 157-166.

EWEA, The European offshore wind industry - key trends and statistics 2013

FINO database available at www.fino.bsh.de

Jinkine, V. \& Ferdinande, V. 1973. A method for predicting the added resistance of fast cargo ships in head waves. International Ship Building Progress, 21. 149-167

Jonkman, J., Butterfield, S., Musial, W. \& Scott, G. 2009. Definition of a 5-MW Reference Wind Turbine for Offshore System Development, National Renewable Energy Laboratory

Lazakis, I., Turan, O. \& Rosendahl, T. 2013. Modelling of vessel and equipment cost for the maintenance activities of an offshore tidal energy array. Proceedings of the PRADS2013, 20-25 October 2013. Changwon City, Korea. 25

Guedes Soares, C., Ferreira, A.M. \& Cunha, C. 1996. Linear models of the time series of significant wave height on the Southwest Coast of Portugal. Coastal Engineering, 29, 149167.

Wilkinson, M. \& Hendriks, B. 2007. Report on Wind Turbine Reliability Profiles. ReliaWind Project. 